\title{
The Ultraviolet Detection of Corona Discharge in Power Transmission Lines
}

\author{
Lan Chen ${ }^{1}$, Lin Lin', Mimi Tian², Xingming Bian', Liming Wang ${ }^{1}$, Zhicheng Guan ${ }^{1}$ \\ ${ }^{1}$ Graduate School at Shenzhen, Tsinghua University, Shenzhen, China \\ ${ }^{2}$ Jibei Electric Power Maintence Company, Jibei Electric Power Company, Limited, Beijing, China \\ Email: chenlan09@mails.tsinghua.edu.cn
}

Received April, 2013

\begin{abstract}
Corona discharge is a common phenomenon in power transmission lines external insulation, and it may cause serious defect if without effective detection. The ultraviolet (UV) imagery technology has been widely used to detect the corona discharge in industry in recent years, but some influence factors' functions are not definite. In this paper, the fracture aluminum strands which is common in power transmission lines were used as the electrode model while a SuperB ultraviolet imager were utilized to detect, the photon count rate was detected with different detect distance, electric field, aluminum strands length and UV gain were applied. Then the multivariate regression analysis (MRA) was taken to calculate the function between the photon count and the factors.
\end{abstract}

Keywords: Corona Discharge; Transmission Lines; Defect Detection; UV Imager; Multivariate Regression Analysis

\section{Introduction}

With the development of Extra High Voltage (EHV) and Ultra High Voltage (UHV), the electromagnetic environment problem caused by corona discharge of conductor was paid attention increased [1-3]. The corona discharge could generate the negative phenomenon such as radio interference, audible noise, ozone-forming, electrochemical reaction [4-6]. The detection of the defect of the corona discharge has been added to the daily inspect in transmission lines in recently years [7].

The corona discharge in the transmission lines often occurred at the high voltage terminal of amour clamp, split clamp, conductor surface and the end of fractured aluminum strands caused by lightning stroke or conductor galloping. And the influence of fractured aluminum strands is extra clear, it not only generate corona discharge by distort the electric field at the end of the strands, but also make a bad influence on the mechanical behavior of the conductor, the defect would make serious harm to transmission security if without fix timely [8]. So it is important to find and fix fractured aluminum strands at the early stage in transmission lines patrol.

The traditional ovular estimate and infrared thermography technology don't have well effect on the fractured aluminum strands detection. For the ovular estimate, people may have different vision disparity and the corona discharge could be find nearly only in intensity at night [9]. While the infrared thermograph technology is able to detect the defect with consecutive electrothermal effect, but the corona discharge must be serious, so it is not promptly for detection of little heat at the early corona stage $[10,11]$. So the infrared thermograph technology is not widely used in the outdoor corona detection in transmission lines.

The ultraviolent imaging technology is able to catch the specific wavelengths photon of UV signal, and then combine with the visible light to decide the corona discharge point. And the strength of discharge is judge by the photon counting rate.

The UV imager was researched and developed to detect the discharge phenomenon by occident at the earliest. It can find the discharge point with small temperature rise at the early discharge stage, is currently one of main methods of discharge detection in the world [12]. From 1980s, the EPRI attempted to utilize the UV imager to test the discharge in the transmission lines [13-15], and have got good achievements. In china it is also have convinced performance in actual use.

The ref $[16,17]$ take the research of corona discharge performance of insulator at different applied voltage, the UV imager was used to measure the discharge. In ref [18], several influence factor of UV imager was studied, such as photon counting rate, detect distance, discharge capacity. Refs $[19,20]$ have discussed the principle of UV imager, and then the UV imager of SuperB was used to detect the corona of electrical equipment in the transmis- sion lines. In ref [21], the UV imager was used to decide the corona inception voltage of the conductor un- 
der dry or rainy conditions.

In this paper, the UV imager type of SuperB, which designed by Ofil company, was used to detect the corona discharge at the top of fractured aluminum strands. And the electric field, length of the strand, detection distance and gain level were researched. Then the MRA was taken to calculate the function between the photon count and the factors.

\section{Introduce of Experiment}

\subsection{Test System}

The experiment was carried out in a shielding hall with a size of $66 \mathrm{~m} \times 30 \mathrm{~m} \times 18 \mathrm{~m}$, and the test model was $4 \times$ LGJ300/40, bundle space was $45 \mathrm{~cm}$, height was 6.8 $\mathrm{m}$, the model picture was showed in Figure 1. And the temperature was $8.4^{\circ} \mathrm{C} \sim 10.8^{\circ} \mathrm{C}$, relative humidity was $35 \% \sim 43 \%$.

The UV imager with type of DayCor SuperB was showed in Figure 2. And the $50 \mathrm{~Hz}$ source with maximum of $1000 \mathrm{kV}$ and $1000 \mathrm{kVA}$ was showed in Figure 3.

And the measurement system schematic diagram was showed in Figure 4.

\subsection{Fractured Aluminum Strands Information}

The fractured aluminum strands (see Figure 5), was set at one of the LGJ300/40 conductor, with different length (see Figure 6).

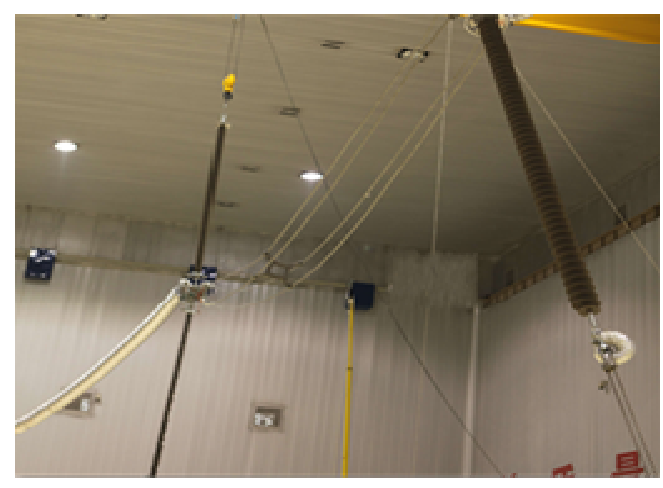

Figure 1. Picture of test model.

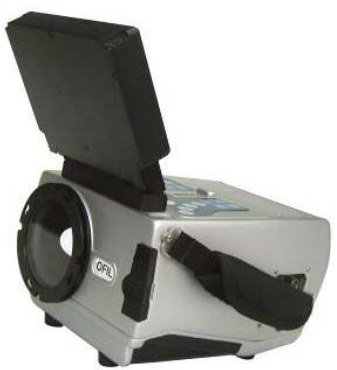

Figure 2. UV imager of SuperB.
And the different strand length, detection distance, applied voltage, UV gain level were show in Table 1. The electric field of the conductor surface (not the top of strand) was calculated by ANSOFT for applied voltage as $10.7 \mathrm{kV} / \mathrm{cm}, 13.6 \mathrm{kV} / \mathrm{cm}, 16.4 \mathrm{kV} / \mathrm{cm}, 19.3 \mathrm{kV} / \mathrm{cm}$, and respectively.

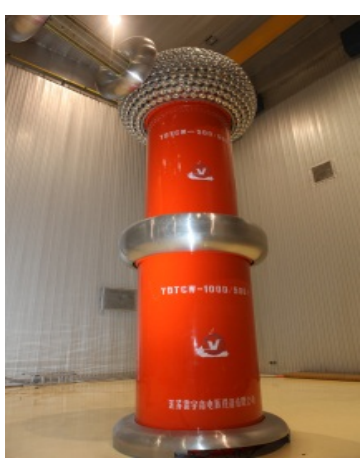

Figure 3. 1000kV transformer.

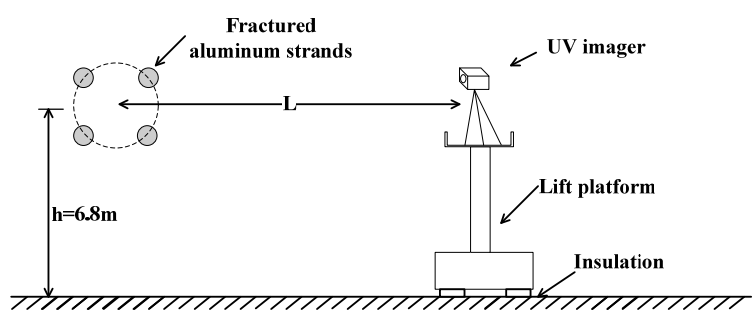

Figure 4. Measurement system schematic diagram.

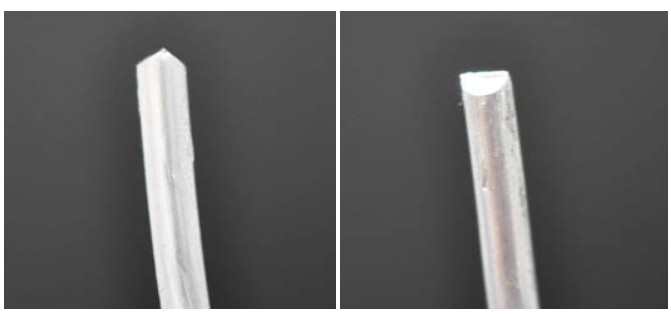

Figure 5. The top of the fractured aluminum strands.

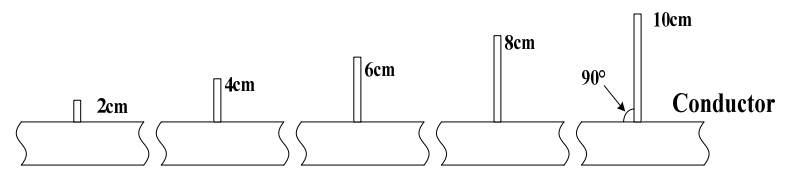

Figure 6. Schematic diagram of fractured aluminum strands.

Table 1. Information of the factor.

\begin{tabular}{cccccc}
\hline Influence factor & \multicolumn{5}{c}{ content } \\
\hline Length of strand (cm) & 2 & 4 & 6 & 8 & 10 \\
Applied voltage (kV) & 150 & 190 & 230 & 270 & \\
Detection distance (m) & 7 & 9 & 11 & 13 & \\
UV gain & 60 & 80 & 100 & 120 & \\
\hline
\end{tabular}




\section{Results and Analysis}

With the different influence factor applied on the strands, the corona phenomenon was detected by the UV imager. Limited by the paper length, one of them was showed in Figure 7.

We noticed in Figure 7 that the photon counting rate would increase with the rise of the applied voltage, such as applied voltage was $150 \mathrm{kV}$ ( with conductor surface electric field is $10.7 \mathrm{kV} / \mathrm{cm}$ ) while the photon counting was 7620 , with the voltage increased to $270 \mathrm{kV}$ ( with field $19.3 \mathrm{kV} / \mathrm{cm}$ ) the photon counting rise at 22660 .

\subsection{Influence of Voltage (Electric Field)}

With the applied voltage of $150 \mathrm{kV}, 190 \mathrm{kV}, 230 \mathrm{kV}$, $270 \mathrm{kV}$, the electric field was $10.7 \mathrm{kV} / \mathrm{cm}, 13.6 \mathrm{kV} / \mathrm{cm}$, $16.4 \mathrm{kV} / \mathrm{cm}, 19.3 \mathrm{kV} / \mathrm{cm}$, respectively, one part of result of experiment was show in Figure 8.

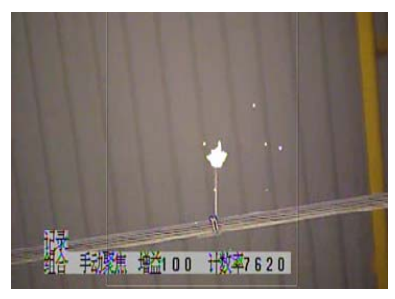

(a) $10.7 \mathrm{kV} / \mathrm{cm}$

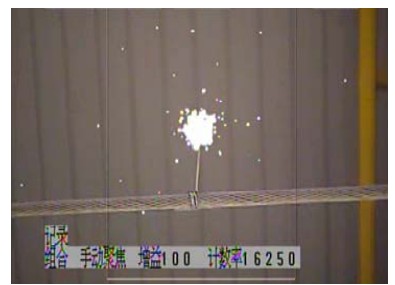

(c) $16.4 \mathrm{kV} / \mathrm{cm}$

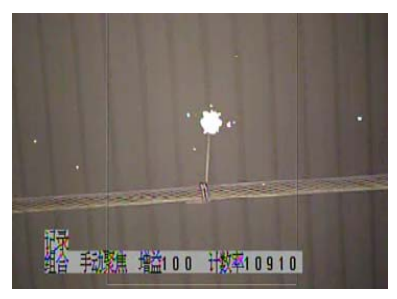

(b) $13.6 \mathrm{kV} / \mathrm{cm}$

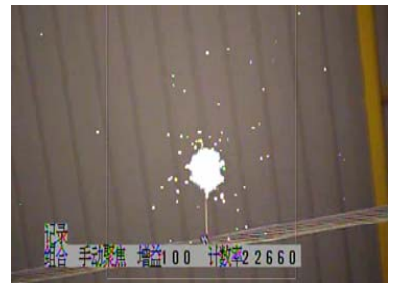

(d) $19.3 \mathrm{kV} / \mathrm{cm}$
Figure 7. Corona discharge at the top of fractured strand with different voltage applied (length of strand is $10 \mathrm{~cm}$, detection distance is $9 \mathrm{~m}$, $\mathrm{UV}$ gain is 100).

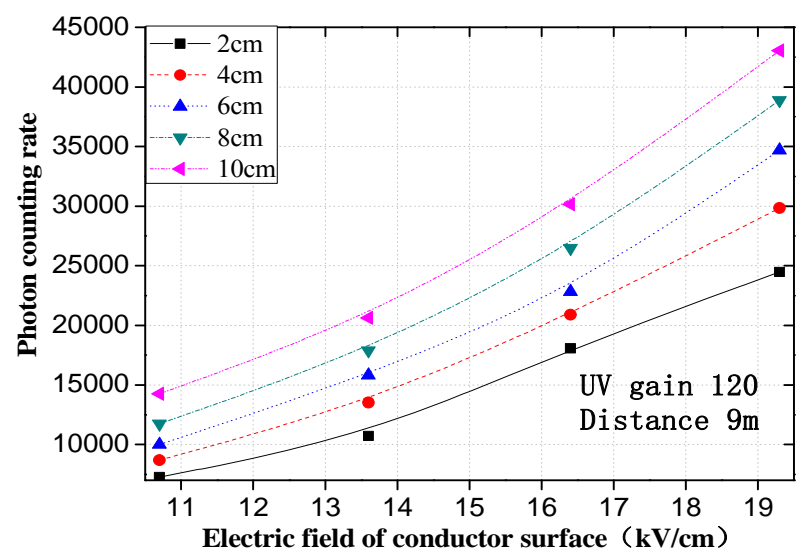

Figure 8. Influence of electric field.

\subsection{Influence of Detection Distance}

With the different detection distance of $7 \mathrm{~m}, 9 \mathrm{~m}, 11 \mathrm{~m}$, $13 \mathrm{~m}$, the results were partly showed in Figure $\mathbf{9}$.

\subsection{Influence of UV Gain}

With the different UV gain was set in the experiment, the results were partly showed in Figure 10. However, the UV gain character is most related to the signal processing module of the UV imager designer, so it may different from other UV imager.

\subsection{Influence of Length of the Strand}

With the different length of strand applied on the conductor, the results were partly showed in Figure 11.

\section{Multivariate Regression Analysis}

MRA was developed from one dimension regression analysis and used to investigate the connection between dependent variable and several independent variables. MRA is considered as an effective mathematical method to solve practical engineering problem.

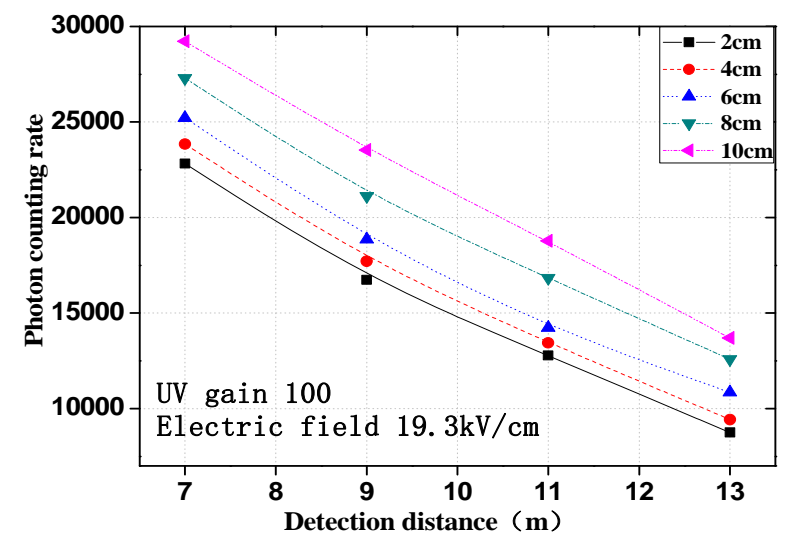

Figure 9. Influence of detection distance.

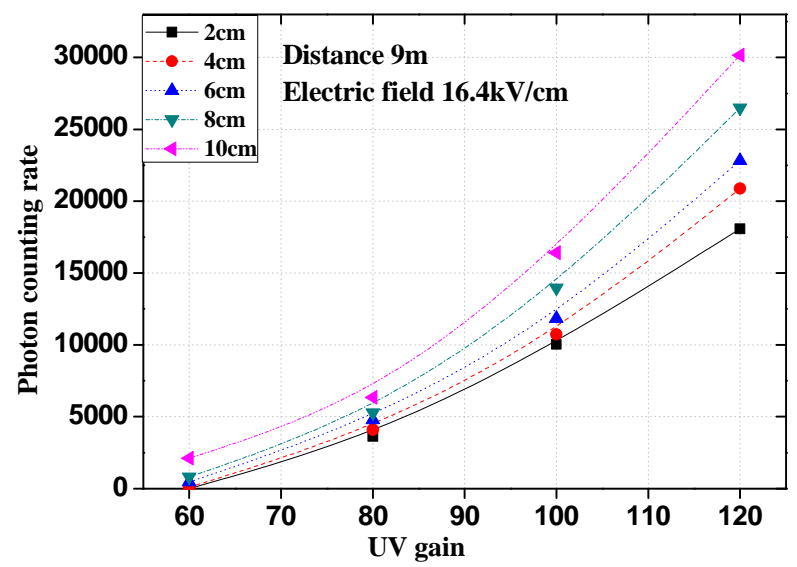

Figure 10. Influence of UV gain. 
The multiple regression prediction equation about the photon counting rate was:

$$
P=\beta_{0}+\beta_{1} \cdot E^{2}+\beta_{2} / L+\beta_{3} \cdot K+\beta_{4} \cdot s
$$

In the equation, electric field was set as $\mathrm{E}, \mathrm{kV} / \mathrm{cm}$; detection distance was set as L, m; UV gain was set as K; length of strand was set as $\mathrm{s}, \mathrm{cm}$.

And the significance test was taken, including R, F and T test, showed in Equation (2), (3) and (4).

$$
\begin{gathered}
R=\sqrt{\sum_{i=1}^{n}\left(\hat{y}_{i}-\bar{y}\right)^{2} / \sum_{i=1}^{n}\left(y_{i}-\bar{y}\right)^{2}} \\
F=\frac{\sum_{i=1}^{n}\left(\hat{y}_{i}-\bar{y}\right)^{2} / m}{\sum_{i=1}^{n}\left(\hat{y}_{i}-y_{i}\right)^{2} /(n-m-1)} \sim F(m, n-m-1) \\
T_{j}=\frac{\left(b_{j}-\beta_{j}\right) / \sqrt{c_{j j}}}{\sqrt{\sum_{i=1}^{n}\left(\hat{y}_{i}-y_{i}\right)^{2} /(n-m-1)}} \sim t(n-m-1)
\end{gathered}
$$

The results of MRA and significance test were display in Table 2.

The result of significance test is well, so the regression equation about photon counting rate is:

$$
\begin{aligned}
P= & -57980+49.29 E^{2}+101230 / L \\
& +347.7 K+754.4 s
\end{aligned}
$$

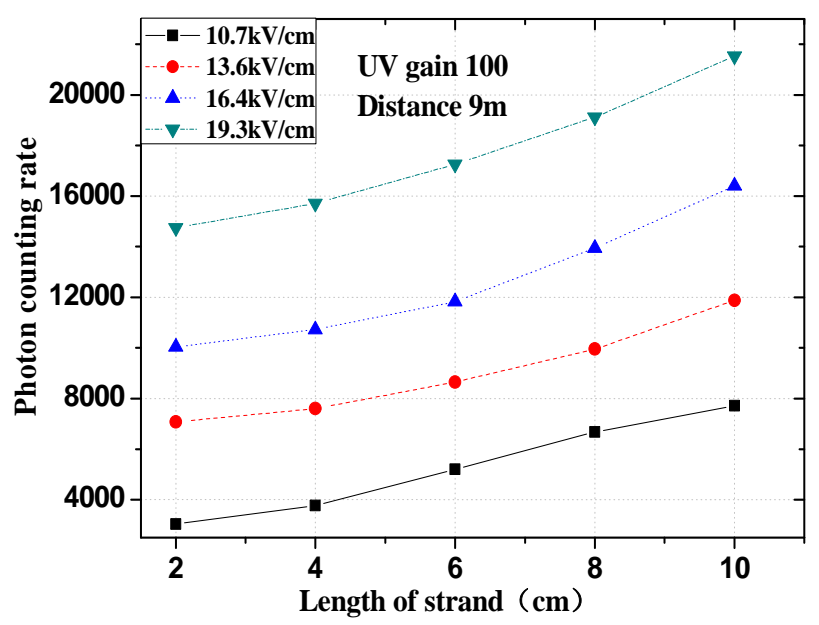

Figure 11. Influence of strand length.

Table 2. Mra about photon counting rate and significance test.

\begin{tabular}{cccccccc}
\hline & $\mathrm{R}$ & $\mathrm{F}$ & \multicolumn{5}{c}{$\mathrm{T}$} \\
\cline { 2 - 8 } & $\mathrm{R}$ & $\mathrm{F}$ & $\beta 0$ & $\beta 1$ & $\beta 2$ & $\beta 3$ & $\beta 4$ \\
\hline Value & 0.934 & 1080 & -57980 & 49.29 & 101230 & 347.7 & 754.4 \\
$\alpha$ & --- & $<0.001$ & $<0.001$ & $<0.001$ & $<0.001$ & $<0.001$ & $<0.001$ \\
\hline
\end{tabular}

\section{Conclusions}

In this work, the fractured aluminum strands was taken for the test model to research the corona discharge detection of UV imager. The influence detect distance, electric field, strands length and UV gain were investigated while the MRA was utilized to summarize the regression equation about the photon counting rate. These conclusions have good contribute to expand UV imaging technology in practical transmission lines patrol of corona discharge.

\section{REFERENCES}

[1] Z. Y. Liu, "Ultra High Voltage Power Grid," Beijing: China Economy Press, 2005, pp. 136-139.

[2] P. S. Maruvada, "Corona Performance of High-voltage Transmission Lines," New York, USA: Research Studies Press Ltd, 2000.

[3] Y. B. Shu and W. Z. Zhang, "Research of Key Technologies for UHV Transmission," Proceedings of the CSEE, Vol. 27, No. 31, 2007, pp. 1-6.

[4] L. Xing, Y. P. Liu, Q. Sun, S. H. You and R. Q. Li, "Measurement Technology of the Corona Loss for 750 $\mathrm{kV}$ Transmission Line," Advances of Power System \& Hydroelectric Engineering, Vol. 27, No. 6, 2011, pp. 17-20.

[5] P. A. Calva and F. C. Espino, "Effect of the Humidity in the Ionic Mobility in Reduced Air-density," IEEE Annual Report Conference on Electrical Insulation and Dielectric Phenomena, Atlanta, America, Vol. 2, 1998, pp. 508-511.

[6] N. Taku, O. Takao, M. Hiroji, M. Hideki, S. Shozo and A. Akihiro, "Charge-voltage Curves of Surge Corona on Transmission Lines: Two Measurement Methods," IEEE Transactions on Power Delivery, Vol. 18, No. 1, 2003, pp. 307-314.

[7] Z. C. Guan and G. L. Wang, "The Projects and Related Key Techniques of Ultra High Voltage Transmission in China," China Southern Power Grid Technology Research, Vol. 1, No. 6, 2005, pp. 12-18.

[8] H. Z. Zhang, "Typical Defects Analysis and Illustrated Books in $500 \mathrm{kV}$ Transmission lines," Beijing: China Electric Power Press, 2009.

[9] Y. C. Cheng, C. R. Li, X. J. Shen, M. Chen and R. H. Chen," Comparison Along Some Methods on Online Detecting of Composite Insulator," High Voltage Engineering, Vol. 30, No. 6, 2004, pp. 35-37.

doi:10.3969/j.issn.1003-6520.2004.06.014

[10] Y. Cai and X. Hu, "State of the Art and Future Trend of Detectors for Infrared Imaging Seekers," Infrared and Laser Engineering, Vol. 35, No. 1, 2006, pp.7-11. doi:10.3969/j.issn.1007-2276.2006.01.002

[11] F. Chen and Y. R. Zhou, "Study on Infrared Image Library and Remote Diagnosis Aid Systems," East China Electric Power, Vol. 36, No. 12, 2008, pp. 55-58.

doi:10.3969/j.issn.1001-9529.2008.12.016

[12] R. S. Arbusov and A. G. Ovsyannikov, "UV-inspection of 
HV Equipment,” ISH 2005, 2005.

[13] W. L. Vosloo, G. R. Stolper and P. Baker. "Daylight Corona Discharge Observation and Recording System," Proceedings of 10th International Symposium on HV Engineering, Montreal, Quebec, Canada, Vol. 6,1997, pp. 161-164.

[14] P. Lindner, "Inspection for Corona and Arcing with the Daycor Camera," Proceeding of World Insulator Congress and Exhibition, Hong Kong, China, 2005.

[15] M. Lindner, S. Elstein, P. Lindner, J. M. Topaz and A. J. Phillips, "Daylight Corona Discharge Imager," Proceedings of 11th International Symposium on High Voltage Engineering, London, UK, 1999, pp. 349-352.

[16] X. Lin and Y. B. Zhang, "Application of Ultraviolet Imaging Technology to the Discharge of High-voltage Corona," Journal of North China Institute of Water Conservancy and Hydroelectric Power, Vol. 32, No. 2, 2011, pp. 80-82. doi:10.3969/j.issn.1002-5634.2011.05.023

[17] Y. Kim and K. Shong, "The Characteristics of UV Strength According to Corona Discharge from Polymer Insulators Using a UV Sensor and Optic Lens," IEEE Transactions on Power Delivery, Vol. 26, No. 3, 2011, pp.
1579-1585.

[18] W.T. Hu and S. H. Wang, "Brief Discussion on Influence Factors in Detecting Corona Discharge by UV Detector," North China Electric Power, No. 1, 2009.

doi:10.3969/j.issn.1003-9171.2009.01.002

[19] I. A. D. Giriantari, "Monitoring the Insulator Condition by On-Line Voltage Distribution Measurement", 2008 International Conference on Condition Monitoring and Diagnosis, Beijing, China, April 21-24, 2008, pp. $392-$ 394.

[20] O. P. Ivanov, V. E. Stepanov, S. V. Smirnov and A. G. Volkovich, "Development of Method for Detection of Alpha Contamination with Using UV-camera "DayCor" by OFIL," Nuclear Science Symposium and Medical Imaging Conference (NSS/MIC), IEEE, 2011, pp. 2192-2194.

[21] L. Chen, X. M. Bian, F. L. Chen, X. B. Meng, L. M Wang and Z. C. Guan, "Method to Judge Corona Inception Voltage of AC Transmission Lines Using Corona Cage," High Voltage Engineering, Vol. 37, No. 1, 2011, pp. 85-90. 